\title{
Do jogo ao game: considerações teóricas e articulações entre game e aprendizagem
}

\section{From traditional to electronic games: theoretical considerations and connections between electronic games and learning}

\author{
Pedro Ribeiro Jr*, Regina Munhoz*, Tatiana Comiotto*, Lia Oliveira** \\ *UDESC, **Universidade do Minho
}

\begin{abstract}
Resumo
Este artigo propõe-se a apresentar ponderações teóricas acerca da relação entre game e aprendizagem, decorrentes de uma pesquisa em andamento. A gamificação teve origem no game. A força atrativa que o game exerce sobre os jovens fundamenta-se na interação. $\mathrm{O}$ processo de gamificação propicia subsídios para que os educadores possam conceber e implementar ações didático-pedagógicas que possibilitam o desenvolvimento de diversas competências, tais como a habilidade de estabelecer padrões, a capacidade de levantar e testar conjecturas, a aptidão de leitura de imagens e de decodificação de representações icônicas, assim como a eficiência no desenvolvimento de estratégias de planejamento.

Palavras chave: Ações didático-pedagógicas, aprendizagem, game, gamificação.
\end{abstract}

\section{Abstract}

This paper aims to present theoretical considerations from an ongoing research about the relationship between electronic games and learning. Gamification derives from electronic games. The attraction power that electronic games have on young people is based on interaction. The gamification process provides support for educators to devise and implement didactic and pedagogical actions that bring about the development of several competences, such as the ability to establish patterns, the capacity to develop and test conjectures, the aptitude to read images and decode iconic representations, as well as the efficiency for the development of planning strategies.

Keywords: Didactic and pedagogical actions, learning, electronic game, gamification.

\section{Introdução}

Na obra Homo Ludens, Huizinga (2000) traça uma linha histórica, na qual, em cada momento, o autor analisa a articulação entre o jogo e os elementos socioculturais existentes, indicando que o jogo tem raízes profundas na esfera sociocultural. De acordo com o pesquisador "encontramos o jogo na cultura, como um elemento dado existente antes da própria cultura, acompanhando-a e marcando-a desde as mais distantes origens até a fase de civilização em que agora nos encontramos" (Huizinga, 2000, p. 6). De fato, "As grandes atividades arquetípicas da sociedade humana são, desde início, inteiramente marcadas pelo jogo" (Huizinga, 2000, p. 7). Além disso, o princípio da cultura se dá por meio do jogo, pois é na forma, e no contexto de jogos, que a sociedade expressa sua interpretação do mundo (Huizinga, 2000). Em suma: a espécie humana é uma espécie que joga, de diversas formas, em momentos variados, para vários fins e em diferentes contextos.

Considerando que as situações de aprendizagem, em circunstâncias formais ou informais, compõem a cultura, e que o jogo e os processos sociais se entrelaçam de maneira reticular, pode-se inferir que aprendizagem e jogo se articulam profundamente.

Com o advento da tecnologia digital surgiu o game, que, essencialmente, é um jogo que se processa por meio dos artefatos tecnológicos, ou de aparelhagem eletrônica específica. A propagação dos games entre os jovens tem alertado investigadores no campo da Educação (Leffa, Bohn, Damasceno \& Marzari, 2012, Mattar, 2010, Ribeiro, 2012), sobretudo quando analisam as posturas adotadas pelos jogadores no momento do jogo. Os gamers demonstram extremo interesse pelos jogos eletrônicos, se empenham com afinco na atividade e dedicam demasiado tempo ao jogar um game (Mattar, 2010).

Nesse contexto, surge a gamificação, como um processo que auxilia na implementação de ações didático-pedagógicas diferenciadas, a fim de adequar os mecanismos de aprendizagem às demandas do estudante contemporâneo.

Com esse fim, é pertinente analisar profundamente os elementos presentes no game, e como esses podem ser inseridos no contexto educacional, na forma de estratégias e práticas didático-pedagógicas que promovam uma aprendizagem significativa.

Jogo: Conceitualização e elementos que o
caracterizam
Qualquer proposta que objetive conceitualizar o jogo
não é suficiente para incluir todos os elementos,
princípios e qualidades que o compõe. Deve-se
considerar inicialmente que o jogo é uma atividade


independente, que "não está ligada a qualquer grau determinado de civilização, ou qualquer concepção do universo" (Huizinga, 2000, p.6). A natureza do jogo não pode ser explicada, exclusivamente, por mecanismos fisiológicos, psicológicos, ou de qualquer outro tipo. Faz-se necessário uma pluralidade de conceitos, oriundos de diferentes setores da ciência, para se compor uma boa compreensão de jogo.

Em Santaella \& Feitoza (2009) encontram-se conceitos de jogo, segundo pesquisadores de diversas áreas das ciências. Observando essas conceitualizações pode-se considerar que as características essenciais presentes no jogo são: a voluntariedade, as regras, o espaço e o tempo, e a evasão da vida real.

Jogar é uma ação voluntária. O indivíduo decide se irá participar da atividade, quando e como esse processo se dará e, até mesmo, se permanecerá no jogo, ou não. Não se impõe a adesão ao sistema, não há obrigatoriedade em juntar-se aos demais participantes para o desenvolvimento da atividade (Retondar, 2007).

As regras são as diretrizes que normatizam as ações dos jogadores, o que pode e o que não pode ser realizado durante a atividade, os comportamentos que são coletivamente aceitos. Em algumas situações as regras podem ser adaptadas, conforme a cultura local, ou para tornar o jogo mais instigante, porém, a linha mestra que delineia as regras é mantida em sua essência. Tais variações estão sujeitas a aprovação coletiva dos participantes (Retondar, 2007).

O jogo desenvolve-se respeitando um limite de espaço e de tempo. O espaço pode ser fisicamente delimitado, como uma rua, uma quadra, um campo, por exemplo, ou pode ser de cunho mais representativo e simbólico, tal como um tabuleiro, a tela do computador - que estabelece, também, um espaço virtual -, dentre outros. O tempo pode ser cronológico, aquele que é medido por meio de artefatos, como o relógio, ampulhetas e outros. Porém, deve-se observar, também, o tempo interno do jogo, que é o tempo do prazer, da diversão, ou seja, o tempo psicológico, que diz respeito à imersão no jogo. Esse tempo não é mensurável por meio de mecanismos de aferição (Retondar, 2007).

A evasão da vida real pode ser entendida como o processo pelo qual o jogador se lança no mundo do jogo e vivencia experiências distintas das que usualmente desenvolve, ou seja, o jogador não realiza as tarefas práticas de sua rotina habitual (Retondar, 2007). De fato, "o jogo não é vida 'corrente' nem vida 'real", é "um intervalo em nossa vida quotidiana" (Huizinga, 2000, p. 11-12).

No jogo verifica-se que há, ainda, elementos informais, tais como a "tensão e a incerteza, [...] o acaso, o espírito lúdico, o espírito agonístico e sentido do "faz-de-conta"” (Retondar, 2007, p. 18).

A incerteza, o acaso e a tensão estão relacionados ao desfecho do jogo, que é imprevisível. Esses elementos encontram-se no processo de interação com o jogo. Cada jogada gera um resultado incerto - nenhuma conclusão pode ser antecipada de maneira comprovadamente acertada -, pois depende da causalidade. A tensão é a sensação resultante dessa incerteza (Retondar, 2007).
O jogo é o próprio espírito lúdico, o mundo imaginário que se contempla no ambiente do jogo, em que o jogador assume as características de um personagem que lhe permite ser algo, ou alguém, diferente do que ele é de fato. Percebe-se aqui uma articulação com o sentido do 'faz de conta'. No jogo, o jogador faz de conta que pode realizar atividades que não são normalmente factíveis no mundo real, ou não compõe seu cotidiano.

Com relação ao espírito agonístico, não se deve entendê-lo como luta ou combate, mas sim na acepção de superação, de competição, de disputa cordial. O sentido de competição no contexto educacional é o da cooperação com o adversário, jogar com o oponente e não contra ele.

Naturalmente existe uma associação bastante íntima entre jogo e competição, pois são o espírito de competição e a superação que levam a obter vitória no jogo. O forte desejo de vitória, de superação, de estar em posição superior, está vinculado à "vontade de potência". Expressão cunhada pelo filósofo Nietzsche (2011), "vontade de potência" é entendido como um forte instinto natural que norteia a evolução do homem, como força motriz da vida, que impulsiona o ser humano, que rege a dinâmica da vida, é o desejo de superar obstáculos.

Com o advento e avanço da tecnologia, das mídias digitais, e dos artefatos resultantes deles, surgiram novos meios de se operacionalizar os jogos, permitindo que esses sejam implementados em ambientes virtuais, de onde surgem os jogos eletrônicos - games. Além de todos os fatores já discutidos, o game reúne outros elementos que intensificam o interesse pelo 'jogar'.

\section{Game: Conceito, surgimento e evolução}

Os Jogos Digitais são jogos - com conceitualização e características como as descritas na seção anterior regidos por algum tipo de programação computacional, na qual utiliza-se uma interface gráfica para instrumentalizar a interação entre jogo e jogador. Todo esse processo é intermediado por aparelhos eletrônicos e mídias digitais - computador e seus periféricos, tablet, smartphone, dentre outros. Esses mecanismos visam estabelecer as diretrizes de ação do jogador, determinar como será a reação do sistema a cada jogada e representar todo o ambiente no qual essa dinâmica se desenvolve (Lucchese \& Ribeiro, 2009).

Nos Jogos Digitais o jogador é absorvido pelo mundo simbólico do jogo. A representação desse mundo figurativo é um constructo que não depende apenas de processamentos cognitivos, e está suportado em algum tipo de material concreto gerado digitalmente. Os recursos digitais, por meio de imagens, sons e outros componentes, contribuem para gerar um modelo representativo constituído por elementos reais, configurando uma representação que se aproxima de algo mais palpável, que apela para os estímulos sensoriais do participante (Lucchese \& Ribeiro, 2009).

A expressão em português que melhor retrata esse tipo de jogo é 'jogo eletrônico', mais amplamente denominado por game. De maneira geral, qualquer jogo que seja processado por meio de aparelhos eletrônicos, tais como consoles, arcades - fliperama -, ou 
computadores, será entendido como game (Santaella \& Feitoza, 2009).

A criação de uma "máquina pensante", capaz de jogar xadrez e interagir com o ser humano e o surgimento de diversas teorias, incluindo os conceitos elaborados pelo Matemático, suscitaram os fundamentos da concepção de game. O primeiro antecessor dos games atuais é o jogo de tênis, elaborado por Willy Higinbothan em 1958, que era jogado em arcades. Em 1962, Russel criou Space War, considerado o primeiro videogame. No ano de 1966, Ralph Baer projetou o primeiro protótipo de um jogo de console, processado na tela de uma TV, a exemplo de como os games são jogados atualmente. Nesse contexto as indústrias do entretenimento empresas cinematográficas e discográficas - voltaram seus interesses para o setor dos jogos eletrônicos, dando origem a empresas de grande atuação no mercado consumidor até os dias atuais (Levis, 1997).

O surgimento da interface gráfica, juntamente com o acesso facilitado aos equipamentos eletrônicos - que se tornaram mais acessíveis ao 'usuário comum' propiciou ao game a oportunidade de conquistar espaço no cotidiano da maioria dos consumidores de tecnologia digital. Desse ponto em diante, o avanço das mídias digitais de comunicação - os sistemas computacionais que dão suporte ao processo de comunicação em massa, tais como a internet - e dos artefatos tecnológicos - o computador portátil, o smartphone e o tablet, dentre outros -, cuja popularização é cada vez maior, promoveram a difusão dos games em grande escala (Levis, 1997).

Tendo em vista a ampla propagação dos games, considera-se de grande valia indagar sobre em quais circunstâncias e de que formas o jogo eletrônico se insere na vida cotidiana do jovem contemporâneo.

\section{Como jovens e game se relacionam: alguns aspectos}

Os games vêm se consolidando como elemento constante no cotidiano dos jovens contemporâneos. Facilmente verifica-se que o game compõe o ambiente sociocultural habitual dos jovens, e que estes são totalmente absorvidos pela atividade, pelo jogo.

Há fortes indicações que o game dificilmente será deposto do lugar por ele conquistado. A renda monetária da indústria dos games já atingiu a casa dos bilhões de dólares por ano. Multidões de jovens visitam as feiras e eventos dedicados aos games, ansiosos e ávidos pelos novos produtos, que são apresentados em meio a um show de luzes e sons (Prensky, 2012). Esse público tem se tornado cada vez maior, e dedica cada vez mais tempo à prática de jogar games. Pelo mundo todo, milhões de pessoas são consideradas jogadoras ativas, que jogam regularmente - cerca de treze horas por semana (McGonigal, 2012).

Sendo assim, convêm investigar os games em relação aos fatores que propiciam tamanho engajamento no ato de jogar. Naturalmente, esse engajamento é fruto do fascínio que o game exerce sobre o jovem da atualidade.

$\mathrm{Na}$ verdade, não só os games, mas o jogo, em sua concepção geral, seduz ao Homem. Dimensionar a atratividade que o game exerce sobre os jovens inclui uma multiplicidade de conceitos e elementos, cujo quadro é constituído por inúmeras variáveis, que se articulam e se integram, compondo um complexo reticular.

O principal fator atrativo no game é a ação, na qual a interatividade surge como protagonista. A interação permite ao jogador controlar um sistema - o jogo. Mesmo que regido por determinadas regras, o jogo é um sistema aberto, sobre o qual o jogador atua e determina, de certa forma, o percurso a ser seguido, ao contrário de ser um mero espectador. Pode-se afirmar, então, que o jogador é um coautor do jogo. De acordo com Levis (1997, p. 182)

$\mathrm{Na}$ verdade, a atração dos jogos de vídeo seria inexplicável se os usuários não valorizassem mais a possibilidade oferecida de controlar o que acontece dentro da tela do que as eventuais imagens espetaculares ou a riqueza da história (Tradução dos autores $\left.^{1}\right)$.

Os objetivos, a dinâmica de imagens, a velocidade, a pontuação, o acaso, a narrativa, são alguns dos diversos parâmetros que constituem a equação que visa mensurar o quanto o game fascina os jovens (Levis, 1997).

Os níveis de complexidade das tarefas, que se apresentam em um crescente, também configuram o quadro de fatores atrativos. Ao passar de um nível para o próximo, o game acrescenta novos desafios e propõe atividades mais elaboradas. Isso incita a curiosidade e o desejo por superar novos obstáculos. Com o objetivo de manter o jogador interessado em jogar, o game, ou cada nível de um game, não pode apresentar missões impossíveis, levando o jogador a desistir, tampouco propor tarefas demasiadamente fáceis, a ponto do jogador não se sentir desafiado. Há de se manter certo nível de equilíbrio entre factível e provocativo (Prensky, 2010).

O processo de interação, viabilizado pelos elementos e qualidades do game, conduz o jogador a imergir profundamente no contexto proposto pelo sistema, cujo ambiente não é o usual do jogador. O momento de evasão da vida real e do 'faz de conta' em um game ocorre quando o jogador incorpora um personagem e vivencia experiências que não são típicas do seu cotidiano. A fim de entender o mecanismo de imersão, como esse processo mobiliza os sentidos e aguça as propriedades cognitivas do jogador, observe a seguinte analogia: é como se um ser vivente, cujo habitat natural é o aéreo, fosse imerso em um ambiente aquático. Essa nova atmosfera - a aquática - estabelece um novo contexto, distinto do aéreo, que permite ao indivíduo explorar experimentos inéditos. Dessa forma, os sentidos - visão, audição, tato e demais - são estimulados, e a atenção do indivíduo se intensifica, pois, enquanto personagem, o jogador observa atentamente tudo que o cerca no ambiente do jogo (Santaella \& Feitoza, 2009).

O ambiente proposto pelo game é um mundo fictício, representado de forma a se aproximar de algo mais concreto, facilitando o processo de imersão no jogo.

\footnotetext{
1 "De hecho, la atracción que ejercen los videojuegos sería inexplicable si los usuarios no valoraran más la posibilidad que ofrecen de controlar lo que sucede dentro de la pantalla que la eventual espectacularidad de las imágenes o la riqueza del relato".
} 
Dessa forma, a imersão torna-se um elemento subjacente que, também, influencia no poder atrativo do game.

$\mathrm{O}$ jogo encerra em si um significado, que satisfaz o jogador em relação a algo que extrapola a esfera do plano físico, biológico ou psicológico (Huizinga, 2000). Os games tocam o jogador em uma dimensão emocional, "satisfazendo as genuínas necessidades humanas [...]. Eles oferecem recompensas [...] nos ensinam, nos inspiram e nos envolvem" (McGonigal, 2012, p. 14).

$\mathrm{O}$ sentido que o jogador encontra no game é um fator circunvizinho ao poder sedutor dos games, que pode ser melhor entendido considerando-se o conceito de interação lúdica significativa. Esse conceito relaciona-se com a dinâmica entre jogador e jogo. A cada ação do jogador, o jogo reage e o jogador atribui significados às respostas fornecidas pelo game.

A interação lúdica significativa em um jogo surge da relação entre a ação do jogador e o desfecho do sistema; é o processo pelo qual um jogador toma medidas no sistema projetado de um jogo e o sistema responde à ação. O significado de uma ação em um jogo reside na relação entre a ação e o resultado (Salen \& Zimmerman, 2012, pp. 49-50).

$\mathrm{O}$ desenvolvimento do projeto de um game, e sua devida execução, fundamenta-se em apresentar um enredo, cujo objetivo é propor os desafios e estabelecer as regras. O contexto em que o jogo se desenvolve encontra-se inserido em um ambiente que é gerado com base na dinâmica entre elementos gráficos e sonoros, e visa indicar o mecanismo de pontuação e fornecer feedback. É na articulação entre tais componentes que se dá a imersão no jogo e que o jogador encontra sentido no game, resultando em intenso engajamento. Todos esses fatores se relacionam, constituindo um complexo, cujo elemento central é a ação.

\section{Game, gamificação e aprendizagem: algumas considerações}

O processo de gamificação fundamenta-se, essencialmente, em utilizar elementos e mecânica de games em situações nas quais a atividade fim não é jogar, com o intuito exclusivo de entretenimento. Na educação, o processo de gamificação não consiste apenas em utilizar um game objetivando desenvolver determinados conceitos acadêmicos, visando à aprendizagem desses conteúdos. Um dos objetivos centrais ao se aplicar o processo de gamificação é promover o engajamento. Percebe-se claramente que o game promove profundo engajamento, levando os usuários a jogar por horas e horas sem parar, de maneira totalmente compenetrada.

Estudos relativos ao conceito de engajamento concentram-se em investigar acerca da relação que o sujeito estabelece com um produto, em que grau de profundidade se dá o envolvimento de um indivíduo com uma determinada tarefa, e como promover interesse e fidelização do sujeito por uma marca ou empresa (Miozzo, 2015). Esse conceito compreende dimensões cognitivas, comportamentais e emocionais (Coelho \& Amantes, 2014, Seixas, Gomes, Melo Filho, \& Rodrigues, 2014).

Esses processos podem ser adaptados e utilizados no ambiente educacional. $\mathrm{O}$ foco do engajamento nesse caso incide em utilizar toda a potencialidade do game-design como base para elaborar e desenvolver atividades didático-pedagógicas que despertem o interesse dos estudantes pelos conteúdos (Fadel, Ulbricht, Batista \& Vanzin, 2014, Mastrocola, 2013). De acordo com Lee \& Hammer (2011, p. 1) a "[...] gamificação pode ser capaz de motivar os alunos a aprender melhor e se preocupar mais com a escola" (Tradução dos autores ${ }^{2}$ ).

Segundo Martins, Nery Filho, Vieira \& Pontes (2014), os principais elementos que constituem o processo de gamificação e suas respectivas funcionalidades são:

- Narrativa: enredo, história, ambiente no qual game se passa, cujo objetivo é contextualizar o jogador quanto às regras e missões;

-Níveis/Fases: processo pelo qual a missão final é fracionada em subtarefas, cujo objetivo é apresentar, gradativamente, missões cada vez mais complexas;

-Desafios/Missões: constituem os objetivos, as situações-problema que devem ser superadas pelo jogador;

- Regras: leis que determinam as diretrizes normativas que padronizam o comportamento dos jogadores;

- Feedback: resposta obtida ao final de uma ação, que possibilita ao participante avaliar sua conduta, verificar se o resultado alcançado foi adequado, ou, até mesmo, reestruturar as estratégias adotadas;

-Competição: interação entre os indivíduos/times, ou consigo, em busca da vitória;

-Engajamento: motivação para participar do jogo;

- Recompensa: gratificação obtida após uma tarefa executada com êxito;

-Pontuação/Progressão: mecanismo que permite ao jogador avançar, ou não, para o próximo nível, ou classificar a posição do jogador em relação aos demais participantes.

A simulação computacional é uma ferramenta bastante útil no sentido de desenvolver estratégias pedagógicas que promovam uma aprendizagem sólida e de boa qualidade. De acordo com Belhot, Figueiredo \& Malavé (2001, p. 448), a simulação ${ }^{3}$ permite "[...] encontrar as respostas às questões importantes e, portanto, torna a simulação uma técnica útil e poderosa para a solução de problemas". A mente humana realiza simulações que visam nos preparar para ações concretas, ou seja, os processos cognitivos são desenvolvidos como um simulador. Os games podem contribuir nessa tarefa, pois possuem atributos que nos permitem classificá-los como metáforas perfeitas de simuladores, gerando situações, ambientes, espaços, acontecimentos e reações que se propõem a representar a realidade (Gee, 2010). Segundo Mattar (2010, p. 24) "[...] todas as simulações educacionais podem ser compreendidas como games bastante rigorosos".

Uma das competências que pode ser desenvolvida através dos games é a habilidade de "descobrir as regras por meio da observação, de teste de hipóteses, de

\footnotetext{
2 "[...] gamification may be able to motivate students to learn better and to care more about school".

${ }^{3}$ Segundo os pesquisadores, simulação consiste em gerar um modelo que representa a realidade de maneira simplificada, que permite ao usuário controlar e manipular facilmente as variáveis e os parâmetros envolvidos no modelo (Belhot, Figueiredo \& Malavé, 2001).
} 
tentativa e erro", (Prensky, 2012, p.74), que essencialmente, constituem os mecanismos utilizados no desenvolvimento de um raciocínio científico. Os 'nativos digitais' não têm o hábito de ler o manual de um jogo para conhecer as regras e como se joga um game. Os jogadores iniciam o jogo, e é por meio da interação entre o jogador e o jogo que os gamers observam, percebem quais são as regras e os padrões, levantam e testam hipóteses (Prensky, 2012). Então, a aprendizagem ocorre na ação, resolvendo problemas e explorando, "por meio de experiências [...] de projetos" (Mattar, 2010, p. 19).

A leitura de imagens e a decodificação de representações icônicas de elementos gráficos é outra habilidade possível de ser desenvolvida pelos games. Os 'novos jovens' desenvolveram uma compreensão visual mais refinada, e eficiência no monitoramento simultâneo. Durante o jogo, o jogador deve estar atento aos diversos elementos gráficos que aparecem na tela $\mathrm{e}$ aos pequenos textos escritos, que complementam as informações. Cabe ao gamer saber utilizar esse conjunto de dados, a fim de elencar quais elementos do game são úteis e relevantes para obter êxito naquela jogada. Toda essa dinâmica exige do jogador extrema concentração e subsidia o desenvolvimento da 'atenção dividida', ou seja, de monitoramento simultâneo de vários elementos. Assim, são estabelecidas as bases fundamentadoras que geram as habilidades relativas ao "processamento paralelo". (Prensky, 2012).

Nos jogos de multijogador ${ }^{4}$, que promovem intensa interação social, os membros da equipe socializam mutuamente suas habilidades concernentes ao jogo, há um trânsito de informações entre os componentes do time. Dessa forma, um jogador aprende com os outros, e o grupo de jogadores cria uma rede de expertises, pois as competências pessoais de cada jogador tornam-se aptidões da equipe toda (Gee, 2010, Mattar, 2010). Todo esse processo tangencia os preceitos relativos à aprendizagem colaborativa.

A categoria de jogos do tipo $\mathrm{RPG}^{5}$ permite aos jogadores projetarem identidades. Ao assumir o papel de um personagem, o jogador projeta sobre seu avatar 6 características e qualidades típicas de alguma classe de indivíduos. Jogos desse gênero tem se mostrado bastante funcionais no sentido de sanar deficiências relativas à leitura, escrita e interpretação de textos, além de desenvolver saberes referentes a outras áreas das ciências (Bittencourt \& Giraffa, 2003).

Os jogos genericamente denominados jogos de estratégia exigem que o jogador anteveja os resultados de cada interação, decida sobre qual elemento do jogo melhor se adequada à tarefa a ser desempenhada e saiba ponderar acerca das perdas e ganhos. Assim, os jogos de estratégia são meios poderosos que viabilizam o desenvolvimento de diversas habilidades cognitivas,

\footnotetext{
${ }^{4}$ Os jogos de multijogador são games em que são constituídas equipes de jogadores, e cada grupo disputa com outras equipes. Diversas pessoas, ao redor do globo, podem participar do jogo simultaneamente (Gee, 2010)

${ }^{5}$ RPG é a sigla utilizada para Role-playing game. Pode ser considerado como "jogo de interpretação de papéis" ou "jogo de representação". Nesse tipo de jogo os jogadores desempenham papéis de personagens e geram narrativas colaborativamente (Mastrocolla, 2013).

${ }^{6}$ Avatar corresponde à personificação de si, que o jogador projeta na tela do computador, no mundo virtual (Mastrocolla, 2013).
}

principalmente àquelas relativas a planejamento, administração e gerenciamento (Gee, 2010).

As práticas didático-pedagógicas a serem adotadas caminham na direção do 'aprender brincando'. Isso não implica que as atividades propostas nesse processo sejam implementadas de forma que o 'jogar' e o 'brincar' corram livremente, sem uma orientação adequada e sem objetivos bem traçados. As tarefas têm como foco a aprendizagem de algum conteúdo científico e a diversão é a base das ações. As atividades são devidamente observadas e orientadas pelo professor. Dessa forma, não deixa de ser trabalho - estudo - e a dinâmica assume um tom mais leve - não penoso e nem enfadonho (Prensky, 2012). O game se enquadra bem nesse perfil, pois todo o design das atividades de um game é concebido tendo em vista propósitos bem delineados, em que a operacionalização das tarefas faz uso de elementos lúdicos.

\section{Considerações finais}

As tecnologias digitais vigentes incidem fortemente na estruturação do perfil psicocognitivo dos estudantes da atualidade. Esses 'novos estudantes' utilizam os recursos digitais e tecnológicos para desenvolver a maioria das suas atividades, incluindo as tarefas acadêmicas.

É urgente que os educadores se adequem a esse novo cenário, e reconfigurem o modelo pedagógico adotado. $\mathrm{O}$ engajamento dos estudantes nas atividades acadêmicas deve ser o norte na implementação de práticas didático-pedagógicas adequadas ao contexto educacional contemporâneo.

O método de gamificação dá suporte para a concepção de atividades didático-pedagógicas que incluem atributos típicos dos games, possibilitando que os conteúdos acadêmicos sejam abordados de acordo com as demandas dos 'novos estudantes'.

Não se quer dizer com isso que o desenvolvimento das tarefas deve estar baseado exclusivamente na utilização de algum game. Pode-se usar um jogo eletrônico projetado para fins educacionais, ou um game comercial. Porém, deve-se observar com devido rigor que as ações sejam adequadamente orientadas, com vistas em atingir um objetivo bem delineado - a aprendizagem de um conteúdo acadêmico.

As mais diversas categorias de games - jogos de ação, de aventura, de interpretação de papéis, de caça de objetos e coisas, de gerenciamento, dentre outros - são bases ricas, repletas de modelos a serem utilizados na geração das atividades educacionais desejadas.

Seja qual for o modelo tomado como fundamentação, mesmo que não se utilize especificamente um game, o pilar das atividades geradas deve ser a ação. As tarefas devem ser planejadas de forma que o estudante seja atuante ao longo de todo o processo. Ao docente cabe a função de orientador, de mediador das atividades junto aos discentes. Os objetivos de cada atividade devem ser traçados com a finalidade de promover a aprendizagem de um determinado conceito científico, ou o desenvolvimento de algum tipo de habilidade acadêmica. As regras devem ser apresentadas de forma clara. Toda tarefa deve conter um sistema de pontuação/progressão, 
e um mecanismo de feedback. No contexto educacional, o feedback, também, deve ser delineado com foco na aprendizagem.

A fim de obter êxito na operacionalização de projetos que incluem atividades gamificadas, os pesquisadores devem se dedicar à análise minuciosa das literaturas pertinentes, e delas extraírem os princípios de aprendizagem contidos nos games.

\section{Agradecimentos}

This article reports research developed within the $\mathrm{PhD}$ Program Technology Enhanced Learning and Societal Challenges, funded by Fundação para a Ciência e Tecnologia, FCT I. P. - Portugal, under contract \# PD/00173/2014.

\section{Referências}

Belhot, R. V., Figueiredo, R. S., \& Malavé, C. O. (2001). $O$ uso da simulação no ensino de engenharia. In Congresso Brasileiro de Ensino de Engenharia, XXIX COBENGE (pp. 445-451).

Bittencourt, J. R., \& Giraffa, L. M. M. (2003). A utilização dos Role-Playing Games Digitais no processo de ensino-aprendizagem. Relatório Técnico n031, Programa de Pós-Graduação em Ciência da Computação, Faculdade de Informática, PUCRS, Porto Alegre, RS, Brasil, 62 p.

Coelho, G. R., \& Amantes, A. (2014). A influência do engajamento sobre a evolução do entendimento dos estudantes em eletricidade. Revista Electrónica de Enseñanza de lãs Ciencias, 13(1), 48-72.

Fadel, L. M., Ulbricht, V. R., Batista, C. R., \& Vanzin, T. (2014). (Orgs.) Gamificação na educação. São Paulo: Pimenta Cultural.

Gee, J. (2010). Bons videojogos + Boa aprendizagem. Colectânea de ensaios sobre os videojogos, a aprendizagem e a literacia. Portugal: Edições Pedágio.

Huizinga, J. (2000). Homo ludens: o jogo como elemento da cultura. (6a ed.). São Paulo: Perspectiva.

Lee, J. J., \& Hammer, J. (2011). Gamification in education: What, how, why bother? Academic exchange quarterly, 15(2), 146.

Leffa, V. J., Bohn, H. I., Damasceno, V. D., \& Marzari, G. Q. (2012). Quando jogar é aprender: o videogame na sala de aula. Revista de Estudos da Linguagem, 20(1), 209-230.

Levis, D. (1997). Los videojuegos, un fenómeno de massas: Qué impacto procude sobre la infancia y la juventud la industria más próspera del sistema audiovisual. Barcelona: Paidós.

Lucchese, F., \& Ribeiro, B. (2009). Conceituação de jogos digitais. Universidade Estadual de Campinas: Campinas.

Martins, T., Nery Filho, J., Vieira, F., \& Pontes, E. (2014). A Gamificação de conteúdos escolares: uma experiência a partir da diversidade cultural brasileira. In X Seminário de Jogos Eletrônicos, Educação e Comunicação.

Mastrocola, V. M. (2013). Doses lúdicas: breves textos sobre o universo dos jogos e entretenimento. São Paulo: Independente.
Mattar, J. (2010). Games em educação: como os nativos digitais aprendem. São Paulo: Person Prentice Hall.

McGonigal, J. (2012). A realidade em jogo: por que os games nos tornam melhores e como eles podem mudar o mundo. Rio de Janeiro: BestSeller.

Miozzo, R. K. (2015). Desenvolvimento de um serviço de informações gamificado como uma estratégia de engajamento do consumidor com a marca. Dissertação de mestrado, Universidade do Vale do Rio dos Sinos, São Leopoldo, RS, Brasil.

Nietzsche, F.W. (2011). Vontade de Potência. Petrópolis: Vozes.

Prensky, M. (2010). Não me atrapalhe, mãe - Eu estou aprendendo! Como os videogames estão preparando nossos filhos para o sucesso no século XXI - e como você pode ajudar! São Paulo: Phorte Editora.

Prensky, M. (2012). Aprendizagem baseada em jogos digitais. São Paulo: SENAC.

Retondar, J. J. M. (2007) Teoria do Jogo: A dimensão lúdica da existência humana. Petrópolis/RJ: Vozes.

Ribeiro, A. L. (2012). Jogos digitais online: ampliando o(s) letramento(s) na sala de aula. In IV Simpósio Hipertexto e tecnologias na educação, p. 1-15.

Salen, K., \& Zimmerman, E. (2012). Regras do Jogo: Fundamentos do Design de Jogos. (Vol. 1). São Paulo: Edgard Blücher Ltda.

Santaella, L., \& Feitoza, M. (Orgs.) (2009). Mapa do jogo: a diversidade cultural dos games. São Paulo: CengageLearning.

Seixas, L. R., Gomes, A. S., Melo Filho, I. J., \& Rodrigues, R. L. (2014). Gamificação como Estratégia no Engajamento de Estudantes do Ensino Fundamental. In Brazilian Symposiumon Computers in Education (Simpósio Brasileiro de Informática na Educação-SBIE) (Vol. 25, No. 1, p. 559). 